\title{
On the Need for an Integrated Large-Scale Methodology of Coastal Management: A Methodological Proposal
}

\author{
Elvira Armenio ${ }^{1, *(1)}$ and Michele Mossa ${ }^{2}(-)$ \\ 1 Regional Agency for the Environmental Prevention and Protection (ARPA Puglia), 70126 Bari, Italy \\ 2 Department of Civil, Environmental, Land, Building Engineering and Chemistry, Polytechnic University of \\ Bari, (DICATECh), 70126 Bari, Italy; michele.mossa@poliba.it \\ * Correspondence: elvira.armenio@gmail.com
}

Received: 18 March 2020; Accepted: 25 May 2020; Published: 28 May 2020

check for updates

\begin{abstract}
Sustainable management of coastal areas involves dealing with problems such as coastal erosion, rapid growth in the rate of urbanization, tourism, environmental degradation associated with industrial and urban activities. Besides consideration is provided for the effects of climate change, whose scenarios also have significant consequences on coastal systems that are already extremely vulnerable and prone to many human pressures. Over the years, several international and national studies have been conducted to deepen the coastal processes. To date-despite considerable efforts-there are still problems. Two relevant priorities emerge: managing coastal risks and ensuring sustainable coastal management. In response to the above-mentioned challenges, it is worthwhile to elaborate an integrated methodology that, basing on the collection, analysis and evaluation of data, may provide an effective guideline for the successful implementation of each action, while providing timely and targeted information for the adoption of governance strategies concerning the prevention and management of marine-coastal risks. In the present study, considering what emerged in the major research projects on the coastal field during the last decades, a methodological proposal is outlined to pursue the principles of the integrated coastal zona management (ICZM) and join the managing coastal risks with sustainable uses focusing on the implementation scale.
\end{abstract}

Keywords: coastal management; coastal risks; erosion; methodology; environment

\section{Introduction}

Although coastal areas represent a small part of the urbanized land territory, they are exposed to the continuous action of various factors, both natural and man-induced, operating on different spatial scales. Among the main human-induced factors, worth mentioning: maritime construction and coastal defense barriers, as the ports, that interfere with sediment dynamics, construction of housing, industrial, recreational infrastructures, interventions in river basins management and regulation of watercourses to provide water resources for drinking water, irrigation and industrial use which induce vegetation alteration and forest drainage [1-4].

Some of the most relevant natural factors are waves height and direction, wind, tide, sediment transport, sediment supply from rivers to the sea, subsidence, sea-level rise, precipitation, frequency and intensity of extreme climatic events, including storms [5-7].

During the 20th century, the above factors combined with population growth, urbanization, and development activities started to affect coastal processes and, consequently, the correlated services, causing degradation of ecosystems, altering coastal dynamics, in particular increasing erosion and coastal risks. 
Several research projects, at both European and international levels, have investigated the problems that afflict the coasts by analyzing and comparing numerous case studies [8-10].

The main findings highlight that the sustainable management of coastal areas has become an unavoidable requirement to protect the coastline, to contain and reduce the ongoing degradation processes avoiding the emergence of new ones [11-14]. The major problem affecting the worldwide coast is erosion. Most erosion phenomena are caused by human activities that have analyzed the coastal dynamics adopting an inadequate spatial scale. Hence, defense interventions to solve erosion problems have induced erosion processes in other coastal stretches, even several kilometers away. Nevertheless, it is also necessary to guarantee the reduction of coastal risks. Most coastal environments around the world are suffering the effects of climate change. Its most relevant consequences are the rise in global sea level and the increase in frequency and intensity of storm events. In this regard, it is worth pointing out that marine floods could amplify beach erosion and saline intrusion thus increasing the susceptibility of coastal populations and ecosystems. These effects would be even more hazardous if combined with a high concentration of people and socioeconomic activities [15-21].

Such insights are also necessary to effectively achieve the objectives of the integrated coastal zone management (ICZM) protocol. The ICZM WATER FRAMEWORK DIRECTIVE Protocol for the Mediterranean establishes an approach, principles and "behavioral guidelines" for Public Administrations, economic actors, enterprises, stakeholders, citizens, to achieve a good degree of sustainability of coastal zone development, through an integrated planning process. In particular, ICZM principles foresee to operate with a unified and integrated vision of the various anthropic and natural elements interacting on the coast with particular emphasis also addressing the issue of coastal erosion and adaptation to climate change [22-26].

From the existing literature, despite there are various methodologies for integrated coastal zone management, but not much attention is paid on its integration with coastal risks and, above all, on the implementation scale.

Considering the scenario outlined, the present work, analyzing what emerged in the major research projects in the field during the last decades, is aimed to propose a methodology for coastal management which also accounts for coastal risks and focuses on the application scale. To this purpose, the study presented is structured in the main following steps:

i. Evaluate significant issues and results of projects and experiences in the national/European/ international scientific framework;

ii. Define an assessment of the most appropriate application scale for effective coastal management basing on the findings of previous studies;

iii. Identify the main analytical phases for a coastal risk management strategy;

iv. Integrate the main steps of coastal risks management into a sustainable coastal methodology;

v. Determine the hierarchical structure of the outlined procedure, the main axes on which it is based and their mutual interconnections;

vi. Highlight the applicability of the methodology, the limits and barriers to its implementation.

The methodology defined is not linked to a specific site, but has a general scope and can, therefore, serve as a useful reference in different areas.

\section{Materials and Methods}

\subsection{Most Relevant International and National Experiences}

Over the years, considerable experience in the academic field has been consolidated on national, European and international levels.

An important Italian project was carried out in the 1980s as part of the "Progetto regime e dinamiche costiere", which led, among other aspects, to the creation of the 1:100,000 scale Atlas of Italian beaches. Afterward, the activity developed with projects of national interest focused on coastal 
dunes, pocket beaches, the morphologic and sedimentological response of the beaches to defense works [27].

Another fundamental reference at the national level is the document produced in 2006 by the Ministry of the Environment and Protection of Land and Sea [28-31]. It defined the framework of the ongoing coastal dynamics along the Italian coasts, the state of solid transport processes, the phenomena of erosion and subsidence, sedimentation and relative sea-level rise. The project points out attention to ports and coastal defense structures, intending to provide guidelines for the preparation of coastal defense plans, studies and research. Among the initiatives on a national scale, the RITMARE [32,33] project (the main Flag Project of the National Research Program in the sector), funded by Italian Ministry of Education, University and Research for the five years 2012-2016 and coordinated by the CNR, plays a particularly important role. It was divided into 7 sub-projects for research and innovation in the fields of marine and coastal environment observation systems, maritime and fishing technologies, interoperable spatial data infrastructures, research structures, maritime spatial planning in the coastal strip, respectively. This project represented a significant source of data, information, technological and modeling support, valuable for evaluations in the field of knowledge development of phenomena, management of the effects of erosion and adaptation to the risk relative to climate change in coastal areas.

The international and European panorama includes several studies and research on coastal management among which BEACHMED, BEACHMED-e, ResMar, CAMP-Italy, COASTANCE, COASTGAP, MAREMED, RICAMA, MICORE, THESEUS, HYDRALAB [34-39]. Such studies have allowed a conspicuous advancement in the knowledge of coastal dynamics phenomena. Many of them have focused on the application aspects of the coastal defense to tackle coastal erosion and risk scenarios for example due to marine flooding [40-42].

Concerning coastal erosion, one of the most relevant European projects is the "Coastal Erosion and Protection in Europe", a monographic compendium on the various European countries regarding the problem of erosion and the solutions adopted to solve it.

Another important study in the European context is Eurosion of 2004. It collects a database on the state of European coasts, through the analysis of about 60 study cases considered representative of European coastal diversity. It has allowed assessing the success of the solutions adopted concerning the most frequent erosion problems. The project then formulated guidelines and recommendations to face the phenomenon in an integrated way $[43,44]$.

Even at the international level, the numerous literature studies on coastal processes reveal that the most critical issue is the problem of coastal erosion. However, erosion rates differ from country to country. In the United States, erosion rates ranging from $0.3 \mathrm{~m}$ to $0.6 \mathrm{~m} /$ year. In the last 100 years, about $86 \%$ of the US east coast has suffered erosion. In China, the rate of erosion is most severe in the northern part of Jiangsu Province, where it is of the order of $85 \mathrm{~m} /$ year; in Hangzhou Bay, the rate is $40 \mathrm{~m} /$ year, while in Tianjin it is 16-56 m/year. Nigeria is losing coast at a rate of 25-30 m/year [45-47].

A project of considerable international relevance is Theseus. The project aims to reduce coastal risks by making safer coastal areas through innovative technologies, ensuring the development of human activities and preserving coastal ecosystems. It involved 31 participants of different nationalities ( 25 from 12 EU member states and 6 international, among which China, Mexico, Russia, Taiwan, Ukraine, USA) and different skills (civil and coastal engineering, marine ecology, sociology, economics, meteorology, computer science and geomatics). The project allowed the definition of a Flood Risk Assessment Methodology based on the "Sources-pathways-receptors-consequences" model, clearly outlining the system exposed (infrastructure, environment and human activities) to flooding and providing a mapping of cause-effect relationships and their mutual dependencies. It has also enabled the development and/or improvement of technological and non-technological solutions for risk management by evaluating innovative techniques and best practices in coastal engineering [48]. 


\subsection{Critical Issues Emerged}

The various projects mentioned converge on the following needs:

i. To apply a multisectoral approach to coastal sustainability able to considerate both natural aspects of the coasts and socioeconomic factors related to their use, integrating risks assessment into coastal management plans;

ii. To pay attention to the implementation spatial scale to properly assess coastal management.

The first point focuses on the need for a management strategy that properly embeds socioeconomic and environmental aspects. This concept is also highlighted in the ICZM protocol and it is one of the pivotal principles of the Maritime Spatial planning directive (2014/89/EU) [49]. The consideration of coastal risks is strictly related to climate change and the consequences it can have on coastal systems. Marine floods and more intense storm surges are examples of this. The second point comes from the awareness underlined in the numerous academic studies, which can be summarized as follows:

- Most erosion issues are caused by human activities that have not taken proper account of coastal dynamics, often because the analyses and evaluations were conducted at too small a scale;

- In most cases, solutions that have solved or mitigated erosion at the local level have induced erosion problems in other coastal stretches or have generated environmental problems.

The latter aspect is essential and demonstrates the importance of carrying out an analysis on an appropriate scale. Precisely, a sufficiently large scale is needed to investigate adequately coastal processes that cause coastal erosion [50-52].

The erosive processes are closely related to the sediment cycle alteration, which, in turn, is determined by natural and anthropic causes $[53,54]$. Among the latter, the construction of artificial reservoirs that altering the sediment balance, the uncontrolled excavations of waterways and the hydraulic-forestry systems that, protecting the soil from erosion, unavoidably reduce the availability of sediment in the bed. In addition, the effects of coastal erosion associated with subsidence phenomena also have relevance to the above processes. Finally, should be mentioned the loss of sediment retained along the end sections of overflowing rivers due to lack of maintenance activities [55,56].

From the above considerations, it results that dealing with coastal management implies have a sufficiently wide-ranging scale of analysis to include and assess properly all the factors influencing coastal balances.

\subsection{Evaluation of Application Scale}

The above considerations lead focusing attention on the application scale of the coastal management strategies [57-59]. To implement coastal engineering interventions able to effectively counter erosion processes, it is necessary to survey at least at the physiographic unit level, so that a resolving action does not have negative effects on nearby coastal zones.

Accordingly, coastal management strategies must be carried out at a large territorial scale and extended on several tens of kilometers to properly assess all existing and/or potential processes, especially those related to risk scenarios.

In this respect, the water framework directive (WFD) 2000/60/EU has introduced an innovative approach in European water legislation, both from an environmental and administrative-management point of view. The directive pursues ambitious objectives: preventing qualitative and quantitative deterioration, improving water status and ensuring sustainable uses based on the long-term protection of available water resources. The WFD—which applies to inland surface waters, transitional waters, coastal waters and groundwater-requires that each member state addresses water protection at the "river basin" level and the territorial reference management unit is identified in the "hydrographic district", defined as an area of land and sea, consisting of one or more neighboring river basins and their groundwater and coastal waters. 
The WFD identifies 110 hydrographic districts in Europe, 7 of which in Italy [60,61]. The concept of "hydrographic district" has been reinstated and strengthens in the subsequent Flood directive (FD) 2007/60/EU. Following the EU directives, water management plans are referred at an application scale that coincides with the hydrographic district. From the outlined framework, it appears convenient assuming the hydrographic district as the reference spatial scale for the implementation of the coastal management methodology. Despite these remarks, coastal area management is still referred to the regional and sub-regional scale to which the management tools, such as regional coastal management plans and coastal defense plans (at the municipal level), are applied. Interconnections with the wider hydrographic district territory, which consists of more than one region, are not taken into accounts. It is worth noting that, generally, a hydrographic district has a coastline extension in the range of tens of thousands of kilometers. On the contrary, at the regional and sub-regional levels, the extent of the coastline is in the order of hundreds and tens of kilometers, respectively. For the above reasons, the methodology proposed in this study is specifically related to the hydrographic district scale of application.

\subsection{Risks Management}

Dealing with natural and anthropic risks involves the evaluation of highly complex aspects and elements, in which the nature of the phenomena underlying the hazard, as well as the interrelationships between the factors influencing the possible consequences, are manifold, interconnected and often difficult to model and estimate. The risk has an interdisciplinary nature. The complexity of its conceptual definition is founded on probabilistic components linked to models of various scientific nature, based on data that are only partially fully quantifiable and, often, referred to assumptions and simplifications. The marine-coastal risks include a wide scenario of potential critical issues for the coasts among which coastal erosion, marine floods and pollution phenomena due to discharges, intense weather and marine events.

The definition of phenomena modeling scenario is a rather complex condition in which it is often necessary to assess, overlap and concatenate processes (domino effect) [62].

More complex is the definition of the following aspects:

- $\quad$ The magnitude of the risk effects, being directly related to vulnerability factors often difficult to quantify;

- The response of the anthropogenic-natural system in terms of resilience assumed as the ability to adapt to the ongoing changes.

It is important to gain initially an analysis of the hazard inherent in natural phenomena which can be derived through a suitable monitoring system able to identify the natural processes in progress. The next step will be the implementation of process modeling. Finally, it will be possible to have an evaluation of the vulnerability of natural systems, i.e., of the elements exposed to risks, aiming to implement procedures to identify risks and manage their consequences.

\subsection{Coastal Risks Strategy: Main Analysis Phases}

The criticalities identified in the fragile coastal areas imply the need to apply a methodology based on integrated management of coastal risks allowing effective support for decisions.

There is a need to adopt appropriate strategies and management for the eroded coasts and, on the other hand, it is necessary to develop scenario assessments so that future interventions along the coasts are supported by an in-depth knowledge framework that can ensure lasting effectiveness.

Precisely, the proposed methodology converges to an integrated management of coastal risks allowing effective decisions support as shown in Figure 1 which illustrates an outline of the main phases of coastal risk management strategies. It can be distinguished three main phases: the first is aimed to acquire a framework of reference knowledge, the second is focused on the data analysis and 
processing and finally the third one contributes to measures definition for planning and programming of interventions.
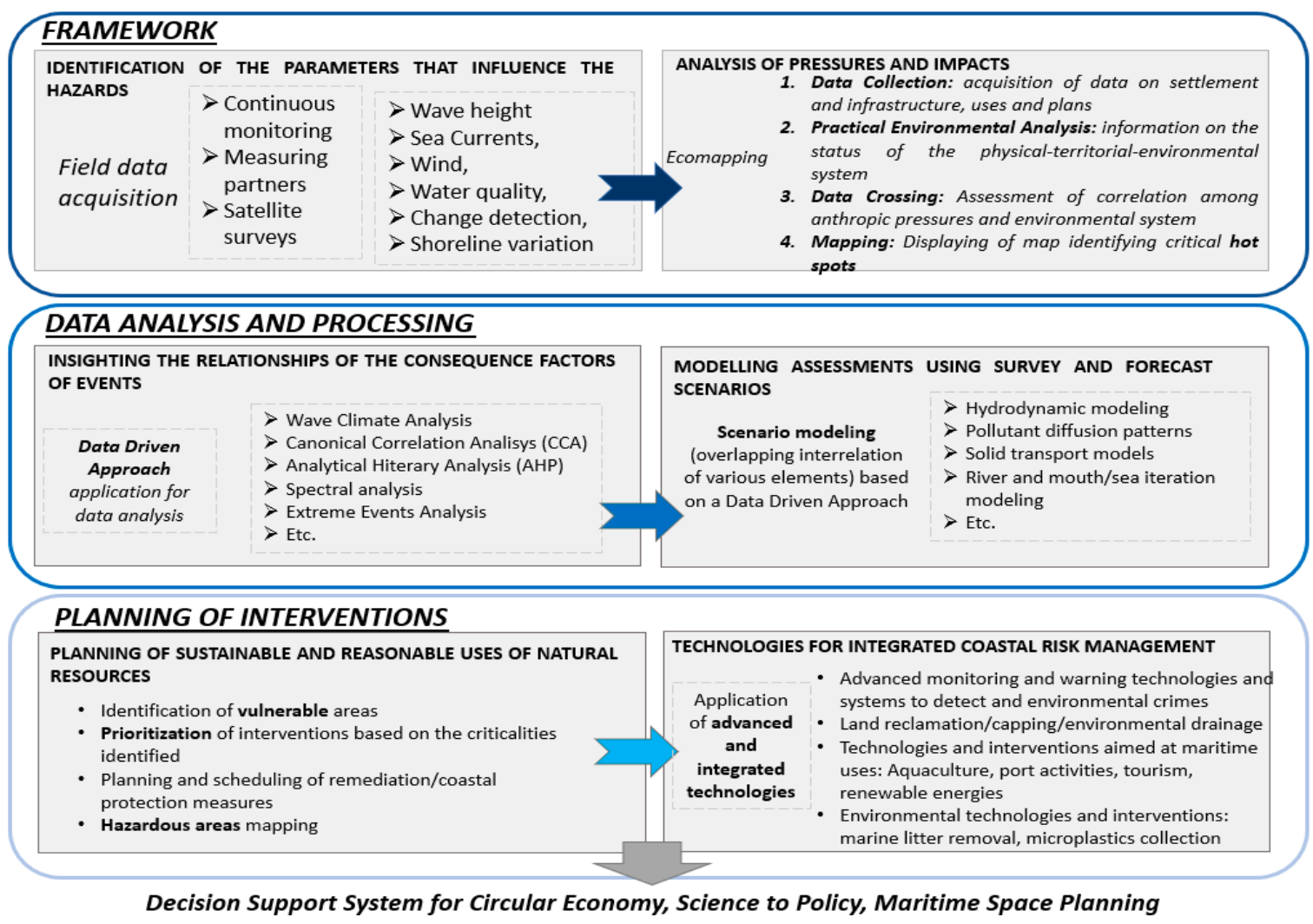

Figure 1. Main analysis phases to support the risks management strategy.

In the evaluation of the knowledge framework, the objective is to obtain as much information as possible on the status of the study area to identify the hazard parameters (i.e., significant waves height and direction, intensity of sea currents, shoreline variations, winds, bathymetric trends, bottom granulometry). These factors can be measured by employing monitoring systems, surveys or lidar investigations. In any case, a sampling protocol should be applied during the monitoring operations, focusing on the data production chain to ensure quality and reliability.

Precisely, data quality is intended as data-based to spatial and temporal resolution acquisitions adequate for the study area and the purpose of the surveys. On the contrary, reliability is related to the application of standard and officially recognized sampling method, the use of certified instrumentation and specialized operators.

The natural features of the study site should be superimposed on the anthropogenic ones. A data collection relating to the productive and infrastructural system will be useful to study the correlation between the anthropic pressures and the environmental system.

Finally, it is advantageous to complete the analysis of the pressures-impacts by applying a map representation through a geographic information system (GIS) and identifying the critical points, i.e., those where more pressures are located and therefore the worst impacts are expected [63].

This first phase will allow the construction of a spatial data infrastructure for a better understanding of the processes in place/expected to support risks and emergency management policies.

Once all the data representative of the environmental-anthropic systems were collected, it is important to extract as much information as possible from the acquired data in order not to incur the data-rich and information poor syndrome. In this regard, it is useful to proceed, first, with the analysis of the acquired measurements to identify all possible correlations, for example by applying wave-climate studies, spectral data analysis, canonical correlation analysis, multi-criteria analysis 
methods. The correlation analysis among the factors that influence the consequences of risk events can be based on a data-driven approach able to identify processes. Subsequently, the detected processes can be further investigated by applying the next steps of scenario modeling. For marine-coastal environments, the main models include hydrodynamic, sediment transport and contaminant diffusion studies [64,65].

In the third phase, based on the previous steps, the management of natural-anthropic risks is achieved through the planning and programming of structural and non-structural measures to ensure the sustainable use of natural resources and through the application of advanced technologies for integrated coastal risk management. Once the most vulnerable areas were identified and the priorities for actions were defined, taking into account the different maritime uses (aquaculture, fisheries, tourism, port activities), the most appropriate technologies will have to be chosen for this purpose.

\section{Results}

\subsection{Methodological Proposal}

Considering what reported in the previous sections, a methodology proposal is described in the following paragraphs. The procedure takes strictly into account the scheme shown in Figure 1 in which the structure was defined considering the conceptual outline of coastal management approach (Figure 2).

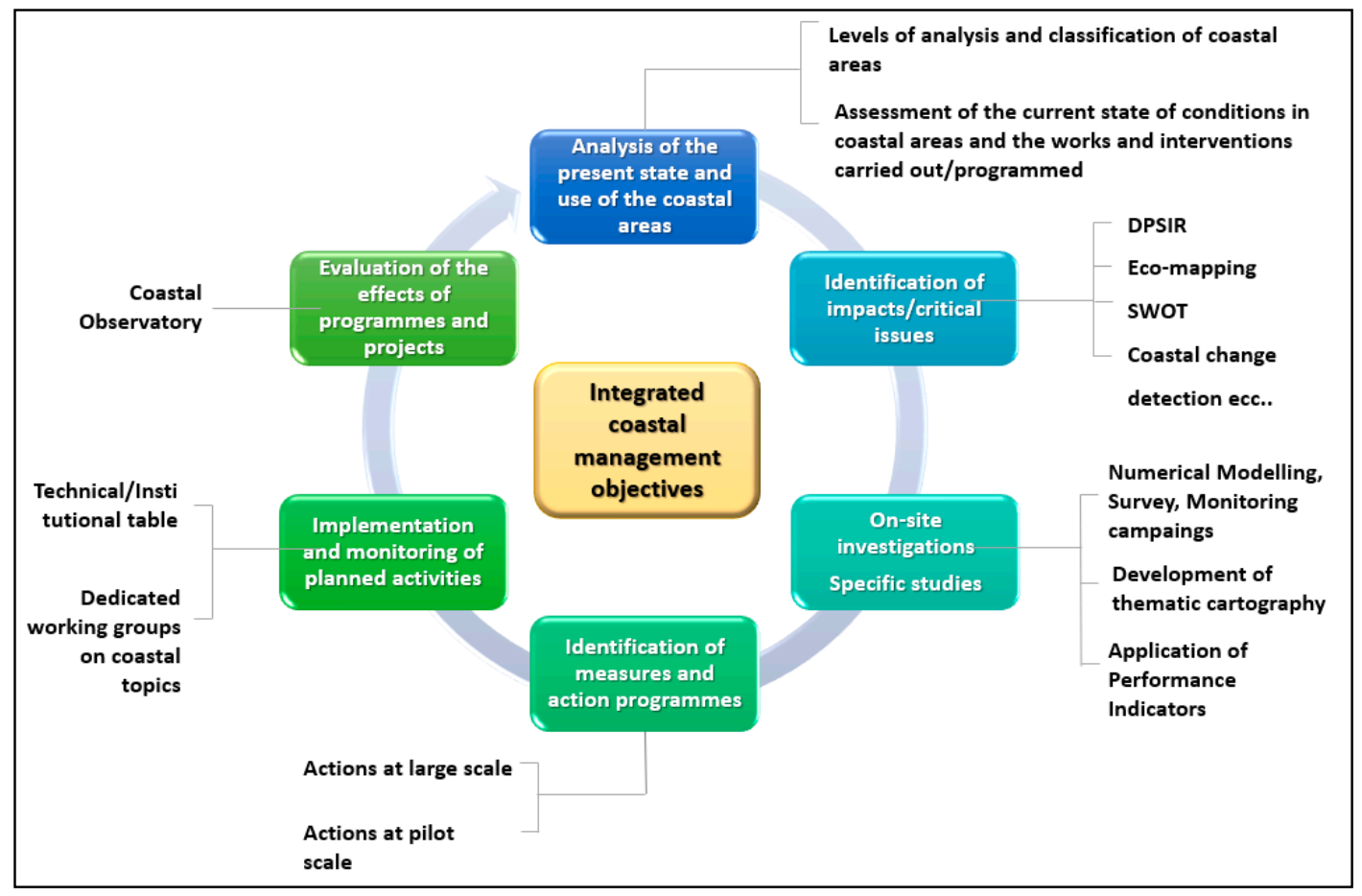

Figure 2. Conceptual outline of coastal management approach.

In Figure 2, the output of each step is linked to the next by establishing a continuous cycle. Starting from this cycle the various phases were better detailed and articulated to achieve a consistent procedure.

The proposed methodology provides for four fundamental systems (Figure 3), which are the pillars on which the articulated logical path based on the implementation of integrated coast management is built. The fundamental systems are the following: system of knowledge, system of analysis and classification, system of instruments and system of actions. Each system is in turn divided into specific axes of activity. 


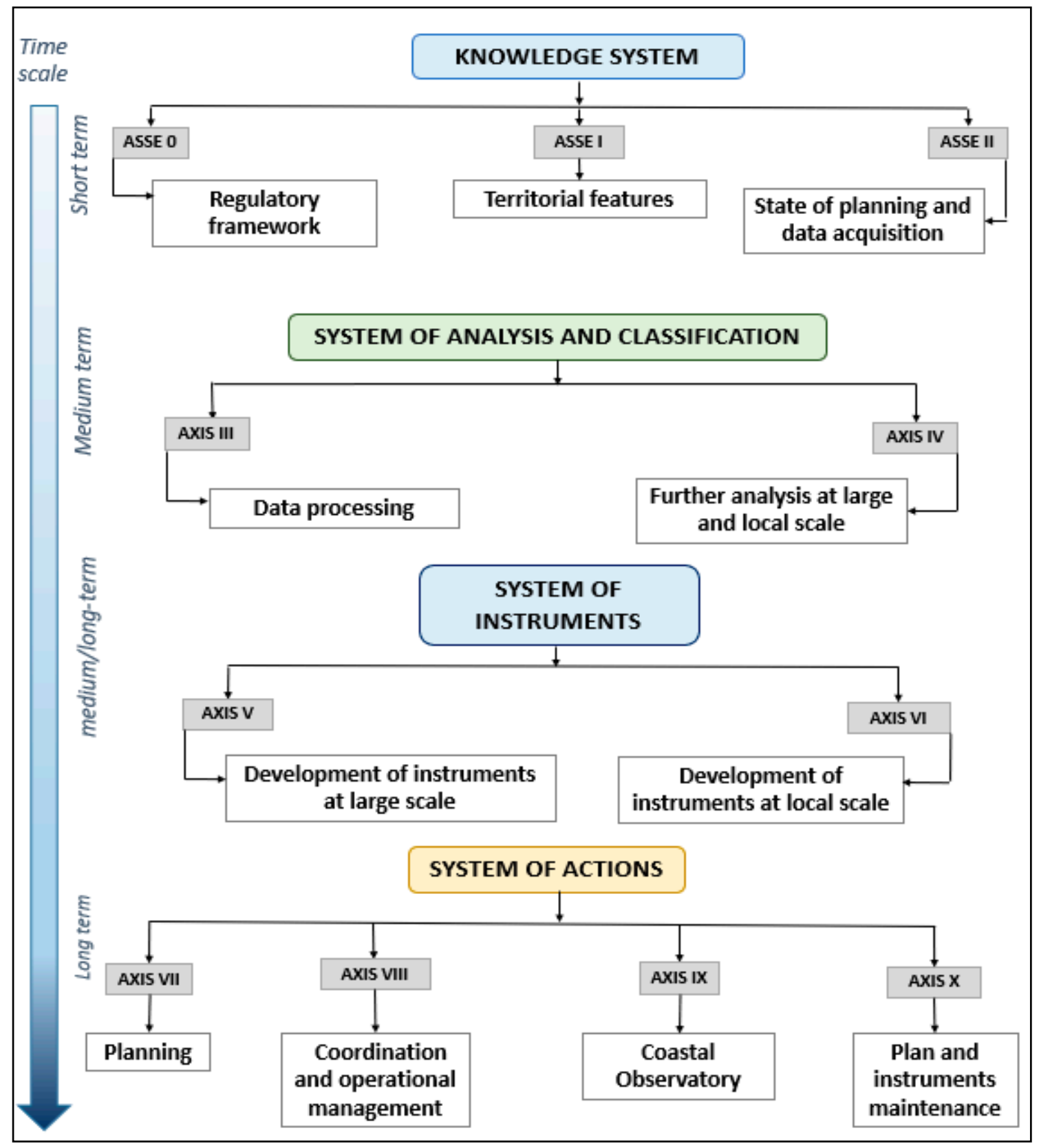

Figure 3. The framework of the methodology for integrated coastal zone management.

\subsection{System of Knowledge}

The starting point of any coastal system analysis is to get a base knowledge of the study site. For this purpose, the first phase of the proposed working program includes the identification of the reference regulatory framework (Axis 0 ), the territorial features (Axis I) and the assessment of planning status (Axis II).

As shown in Figure 4, it is desirable an updating of the regulatory framework and the collection of existing features of coastal areas to allow the most effective support for the definition of future scenarios. 


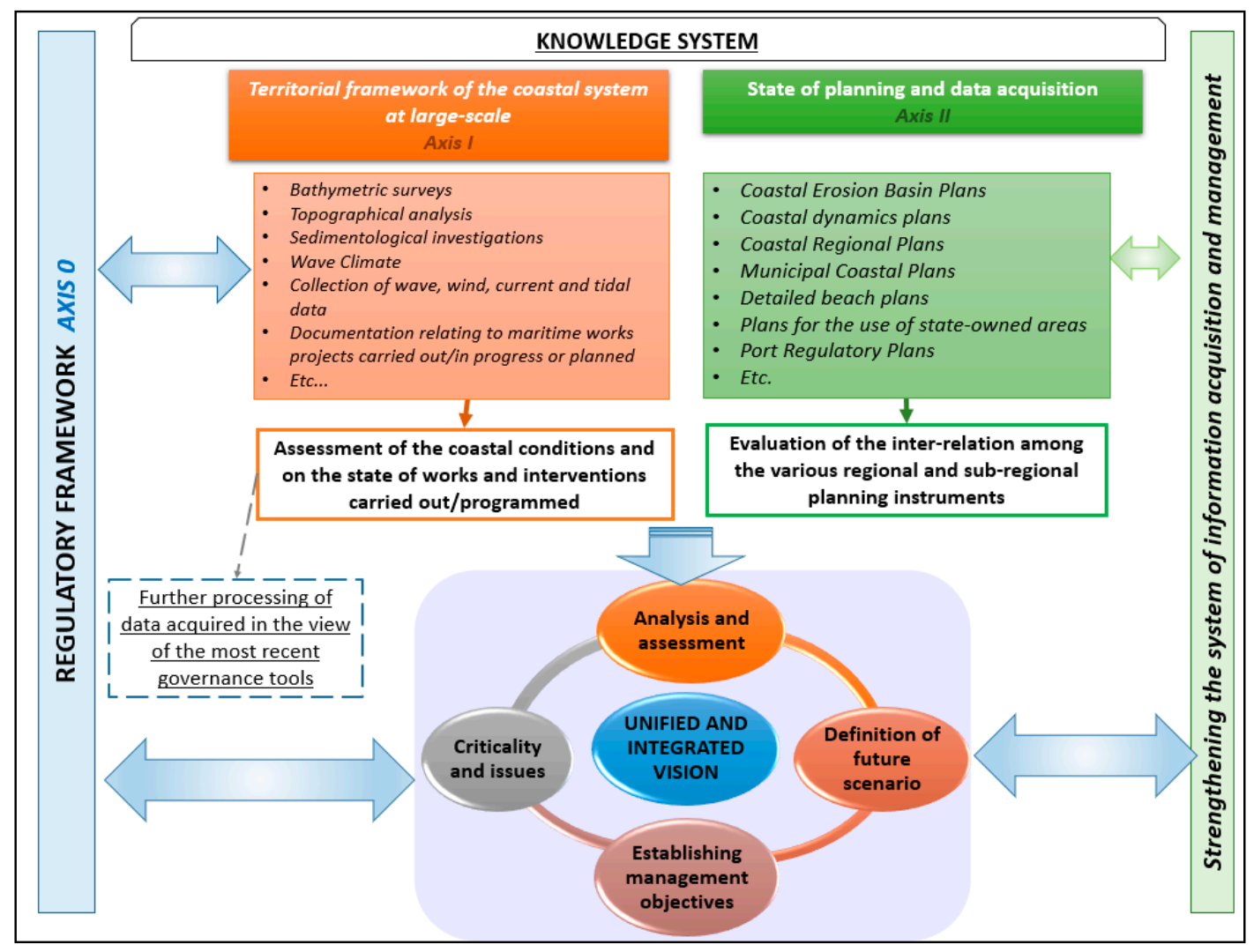

Figure 4. Schematic view of contents of the knowledge system.

In this respect, the first step will be analyzing existing planning tools and their state of implementation, for example, regional and municipal coastal management plans and beaches nourishment plans.

The tasks described above aim to assess the relationship between the various regional and sub-regional planning tools and their coordination with district basin planning.

In addition, it is useful to acquire maps and information already available in coastal areas (bathymetric, topographic, sedimentological, meteorological, hydrodynamical). The information collected will constitute an important knowledge base to support coastal management.

In the view of the most recent governance tools (national guidelines, ICZM protocol, etc.), the further acquisition of data processing should be appropriately added to the existing ones to fully understand the phenomena, both environmental and socioeconomic, that could compromise the protection of the coastal system.

It is important to achieve a unified and integrated vision about the coast (Figure 4) by identifying the future scenarios, the management goals, the criticalities and issues of the coast.

\subsection{Analysis and Classification System}

The data collection and the findings of the knowledge system will be used for the next level of the methodology which provides for the analysis and classification system (Figure 5). It consists of Axis III relating to data processing and Axis IV relating to large-scale investigations. At this stage, the reference physiographic units and sub-units will be identified and the criteria for the analysis and attribution of the coastal system classification levels will be defined. The two phases are closely linked. Based on the information collected during the activities of the previous knowledge system, a first study of the data will be carried out to have a general characterization of the typology of the coasts followed by an evaluation of their evolution with the identification of coastal areas in progress or retreat. 


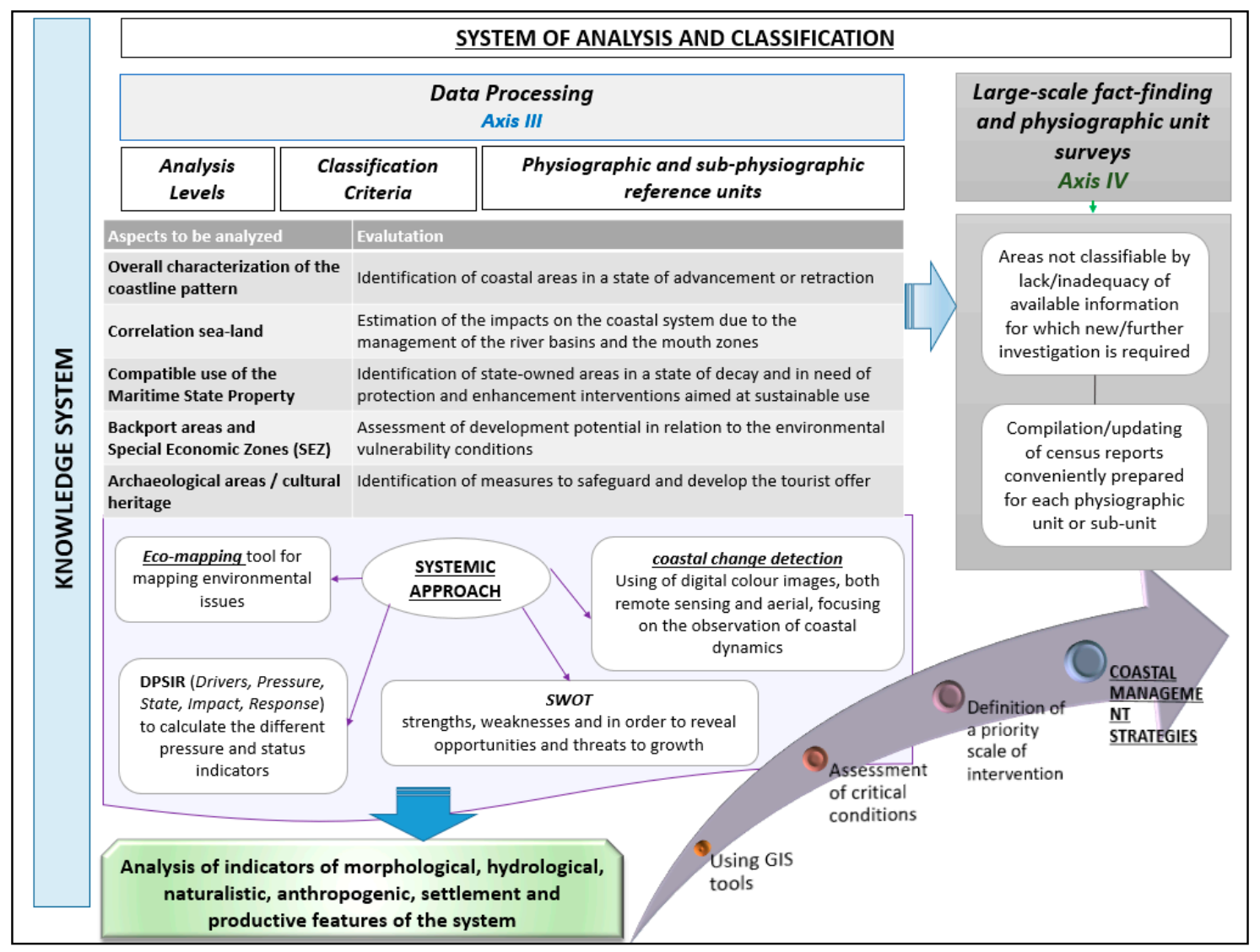

Figure 5. Schematic view of contents of the analysis and classification system.

Following, the analysis and detailed investigations of the coastal areas will allow to identify further existing critical issues. For example, to this end, the influence of river basin management on the state of the coasts will also be considered, identifying, the coastal areas subject to alteration caused by changes in the solid transport of river auctions or even areas where restoration of the rivers solid transport to reactivate the natural beaches nourishment. In addition, attention will be paid to the land-sea correlation or the estimation of the impacts deriving from the management of the river basins and the mouth-sea areas.

At the end of this phase, any unclassifiable areas due to the lack/inadequacy of available information will be identified to plan new/further investigations. For these areas, as envisaged by Axis IV, various in-depth studies at physiographic or small-scale unit can be carried out to investigate on coastline evolution, instability phenomena, hydraulic works, etc. Specific analyses can be applied among which geomorphologic and geophysical surveys, assessment of morphodynamic areas, subsidence and salinization phenomena of coastal areas, studies of the meteorological climate, solid river and coastal transport, mouth and coastline evolution, extreme sea events.

The expected result is a classification of the coastal basins, both relative to the low and the high coasts, deriving from the analysis of the morphologic, hydrological, naturalistic, anthropic, settlement. GIS tools can be also used to facilitate this task. At the end of the analysis described, any critical conditions that emerged will be assessed as the implementation strategy for the management of the coastal area by defining a priority scale of intervention.

\subsection{Instrument System}

The System of Instruments provides for the development both of wide (Axis V) and local scale (Axis VI) instruments (Figure 3). The fundamental instruments for coastal zones management are the risk maps. 
From the findings of the system of analysis and classification it will be possible to implement Risk and Hazard Maps for whose perimeter will be considered a significant amount of data and technical-scientific knowledge, as well as complex processing such as analysis hydrological-meteorological and sediment transport studies (Figure 6). For the aforementioned maps, different levels of vulnerability will be identified with reference to heavily populated and degraded coasts and which need defense and safeguarding in relation, for example, to the risk of coastal erosion, sediment accumulation, coastal flooding, subsidence and intrusion of the salt wedge. In this phase, considering what emerged from the analysis and classification of coastal systems, thematic maps and a set of environmental Performance Indicators can be developed to make qualitative-quantitative comparisons among the individual coastal areas (Figure 6). Examples of quantitative indicators related to a coastal area are shoreline change rate, coastal elevation, land use/land cover, coastline landforms/features, extreme weather events, anthropogenic settlements. On the other hand, among the properly qualitative indicators include efficiency level of interventions, degree of acceptance of coastal management choices, the participation of stakeholders and communities.

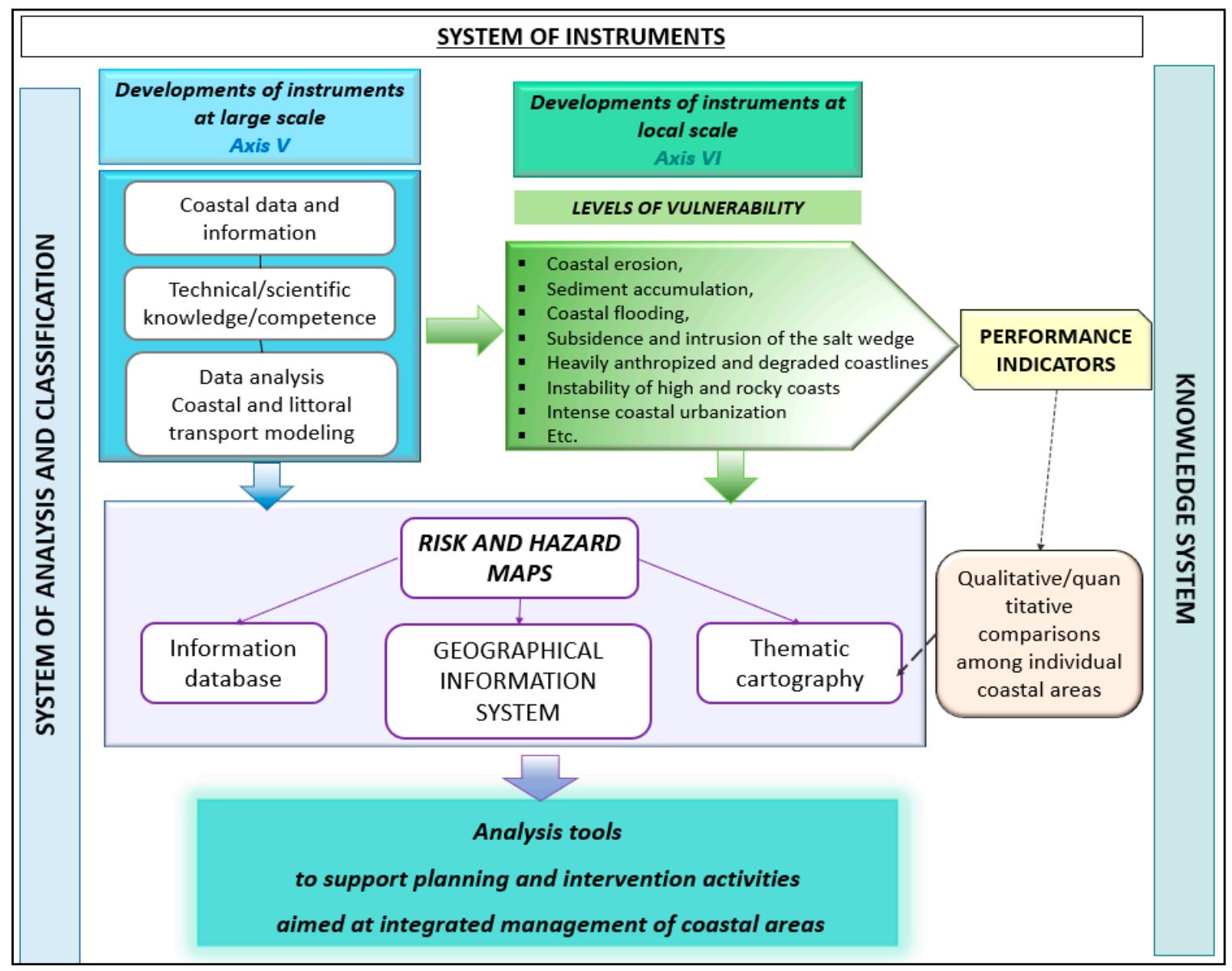

Figure 6. Schematic view of contents of the analysis and classification system.

All the data and information that emerged on the coastal system, as also the defined Performance Indicators adopted, will be organized in an information database for the collection, integration and standardization of information relating to the knowledge base of the coastal areas. The database, as well as the cartography produced in this phase, will be a useful management tool to support planning and intervention activities aimed at integrated management of coastal areas. 


\subsection{Action System}

As shown in Figure 3, the system of actions includes the planning activity (Axis VII), the coordination and operational management activity (Axis VIII), the development of the coastal observatory for the control and monitoring activities (Axis IX) and the Maintenance activities of the plan and the other Instruments (Axis X). Figure 7 shows a schematic view of the contents of the action system.

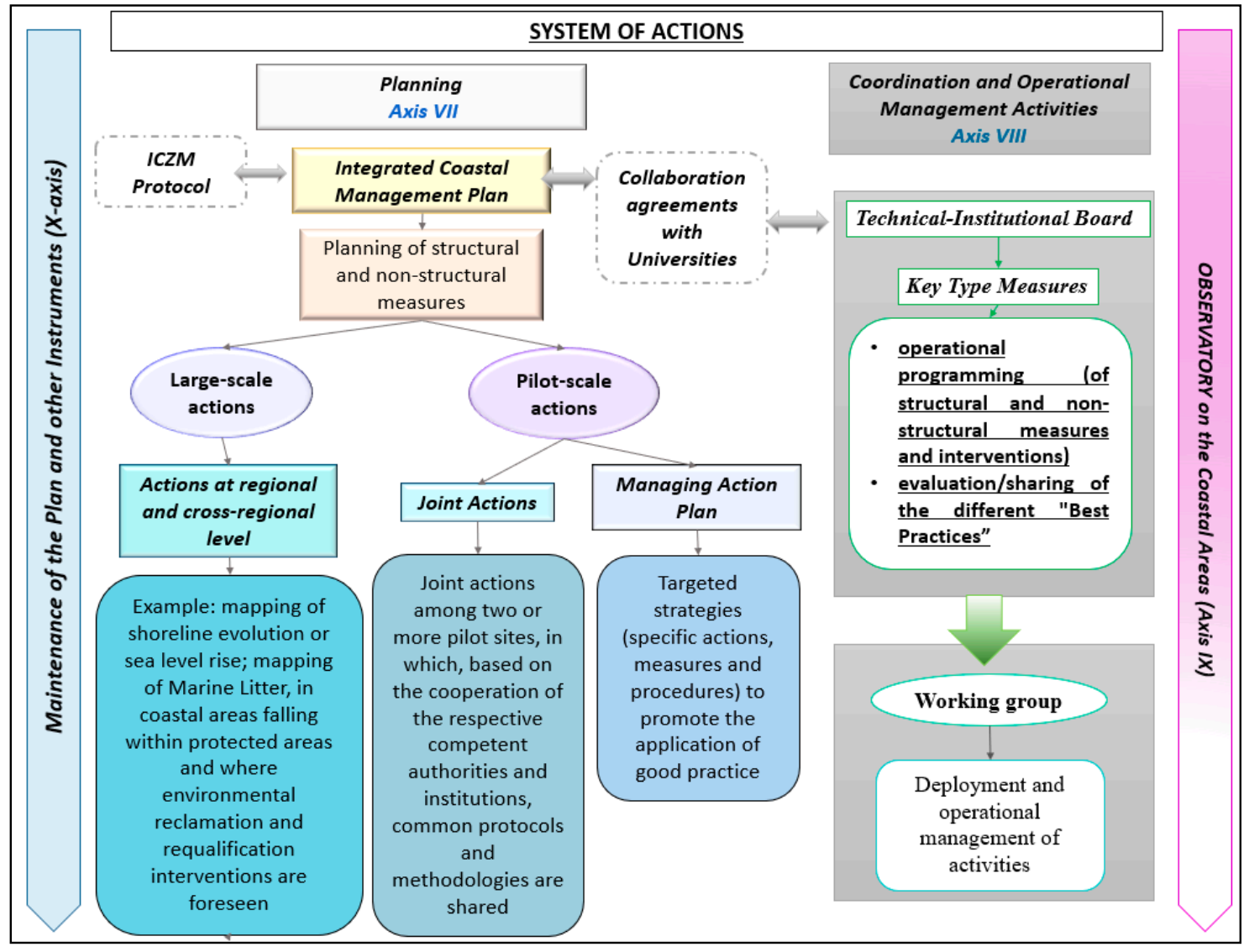

Figure 7. Schematic view of the Actions System.

Based on the activities described in the previous axes, the planning and programming of the measures (structural and non-structural) and the sustainable actions will be defined to balance, from medium to long term, the environmental, economic, social, cultural and recreational within the limits imposed by natural dynamics following the provisions of the ICZM.

The planning activity (Axis VIII) will mainly focus on the elaboration of the "integrated coastal management plan" (hereinafter referred to as the "plan") which, will be included in a planning framework at the district basin-scale to favor an overall strategic vision to protect and enhance coastal areas, both as water and soil resources. In this regard, the general objectives of the plan, nature, the strategy, the aims, and the logical-operational sequence for its implementation must be defined.

The plan must be prefigured as a regulatory, technical-operational and financial instrument whose main purposes will be:

i. To check the current condition of the coast of the Regions belonging to the large-scale area of interest;

ii. To evaluate the possibilities for the sustainable and rational use of the marine and land parts of coastal areas,

iii. To identify the critical issues and the management needs of the coast; 
iv. To establish a program of interventions, the actions of safeguarding and protecting the coast, with the classification of the works to be carried out in the context of the planning activity for the overall enhancement of the coast;

v. To define the temporal and economic programming of the interventions concerning the financial coverage to which the EU, the State, the Regions, the Municipalities and the private subjects contribute.

The plan should provide an overview of the district's coastal areas and define priorities for small-scale actions. For the latter case, for example, in the areas with greater criticality, a managing action plan can be implemented for the development of targeted strategies (focused actions, measures and procedures) and joint actions between two or more pilot sites, providing for cooperation among Institutions/authorities to share common protocols or methodologies aiming the application of good practices about the sustainable management of coastal areas.

\subsection{Integrating Coastal Risks into Sustainable Coastal Management}

Regarding the integrations between the identification of coastal risks and the sustainable coastal management, the following should be highlighted. The methodological proposal incorporates what is set out in Figure 1. The first "framework" phase of the scheme in Figure 1 requires a collection of all relevant surveys data to describe the factors influencing the risks. It includes the acquisition of monitoring data, survey campaigns, in situ measurements on the specific parameters to coastal environments. This first phase was merged into the knowledge system of the proposed methodology (Figure 3), which has planned the collection of all useful information already available in coastal areas (bathymetric, topographic, sedimentological, meteorological, hydrodynamic). The "Data Analysis and Processing System" shown in Figure 1, which represents a fundamental element for the identification of characteristic processes and the implementation of scenario modeling, is included in the "analysis and classification system" provided for in the methodological proposal in Figure 3, which is aimed to the processing and classification of coastal area data.

The third phase related to "planning and Intervention" reported in Figure 1, which is based on the definition of planning actions for the sustainable use of natural resources and the application of advanced technologies for risk management, is provided for in the "action system" (Figure 3) which foresees the planning of all these measures within the coastal management plan.

\section{Discussion}

The proposed methodology is based on a hierarchical structure that logically and sequentially outlines the stages involved (grouped in Axes) in coastal management. As regards the applicability of the proposed method, the basic steps can be synthesized as follows. The first step aims to conduct a recognition of the coastal areas' condition and the available data, as indicated in Axes I-II. As already pointed out in the previous sections, the application of the method refers to a rather large area (hydrographic district scale) and then the data collection for such a large territory can be time-consuming, represents a barrier to the effective application of the methodology. At this stage, it is advisable to have a forceful collaboration among the various authorities/institutions in data sharing. The next step in the application of the method consists in the analysis and evaluation of the acquired data (Axis III and IV) aimed to assess their comparability and adaptability to properly describe the coastal territory, highlighting missing or insufficient data. In this context, any additional surveys needed for data collection and the sites to which they will be applied will be identified.

Based on the findings, in the next phase (Axis IV and V) the instruments to be applied are defined both on an extended scale (district basin) and in pilot areas (Axis V-VI). The purpose is to achieve a complete overview of the entire area in the hydrographic district, with particular focus on the most critical areas, i.e., those subject to increased anthropogenic pressures. 
Concerning the hydrographic district area, for example, it is possible to use satellite images for the evaluation of the shoreline trend or change detection analysis. At the hot-spot level, coastal vulnerability analysis, eco mapping, and DPSIR methods can be applied (as better explain subsequently).

The last step in applying the approach proposed is the most important as it includes the definition of the key tasks to be used for coastal management, in particular the implementation of a coastal management plan (Axis VII), the establishment of a coastal observatory (Axis IX) and monitoring and coordination activities in supporting the execution of the plan (Axis VIII and X).

The methodology exposed, although it follows a logical path obvious and simple, in practice faces some barriers. As regards the main difficulties and limitations in applying the method, the following should be highlighted.

The methodology is based on the awareness that effective coastal management that aims to conjugate sustainability and risk assessment must approach a large coastal territory, on a district basin scale. This implies that the various authorities and institutions operating at regional and sub-regional level (municipalities, local authorities, provinces) must cooperate in a synergic way by promoting the exchange of data and information already available on the territory they administer and by initiating fruitful dialogs. The collection of data allows defining the starting knowledge base on which to evaluate the intrinsic risks of an area and build the whole process of coastal management. To overcome any criticalities at this phase and facilitating the sharing of data and the most effective comparison among stakeholders, social partners and all the actors involved in various roles in coastal strategy, Axis IX provides for the establishment of the observatory on coastal management. In this regard, in an integrated perspective of "knowledge and control" of management on a large-scale area, the observatory will have a data collection section to integrate, in a single database, all the environmental information managed separately by each Authorities/Institutions and share it. From a merely technical point of view, a possible limitation is related to the need to compare data that may have various formats and different temporal and spatial scales of observation. The initial effort is aimed to gather all the data into just one database will be an expensive process. The database can be updated and compiled with the new data that will be acquired time-by-time and, in this way, it will become a network able to collect all data on monitor coastal dynamics, water resources and ecosystems. The observatory will also have further tasks to undertake. Specifically, it will have to supervise activities both on the state of implementation of the planned measures and on the effectiveness of the interventions, and, at the same time, on the evolution of the integrated coastal zone management processes.

Another criticality is related to the evaluation of the significant effects that the actions of the plan can have both on the coasts and the areas adjacent to them.

On the issue is worth noting that a limitation often found in the implementation of coastal management is that specific performance measures representative of social aspects is often lacking. The identification of indicators for socioeconomic factors enhances the set of measures to improve planning and assess progress over a broader scope than the use of environmental performance measures alone. Any environmental program must incorporate social concerns into its action plan. In this context, some of the indicators to be considered may also include social conditions and cultural traditions, habitat/ecological value change, human use/activity, resource extraction activities.

To overcome this limitation, in the proposed methodology, the observatory has a key role in guarantee the participation of stakeholders and social partners and promoting the widest synergies between them. The most effective matching of the response to social conditions and environmental dynamics can only benefit the based decision-making process on sustainable use of resources and development practices. In the overview presented, the observatory will become the reference point, on a large scale, for local authorities and regional actors, on issues related to rational and sustainable use as well as the integrated management of the coastal areas. One aspect to focus on is the critical areas that may be present along the coast such as ports or production sites. In such zones, it is necessary to combine human activities (transport of goods and people, shipbuilding, dredging, etc.) and the correlated economic development with the need to protect neighboring coastal areas. Consequently, 
the classification and analysis will also concern the settlement and socioeconomic aspects of the coastal strip (land use, forecast and development prospects, demographic trend, mobility and traffic flows, etc.) to integrate environmental protection interventions with the enhancement of the social context and economic productivity. For these cases, Axis IV provides for the application of detailed procedures to be applied on a local scale.

In particular, the classification can be implemented through a systemic approach as suggested by the ICZM protocol. For example, the DPSIR analysis model (drivers, pressure, state, impact, response) can be applied to calculate the various pressure and status indicators to assess the susceptibility and propensity to coastal erosion or development or degradation. The DPSIR model, introduced by the European Environment Agency (EEA) in 1995, represents the most shared methodological structure to describe the interactions between society and the environment. Due to its simplicity and the possibility of application at any scale, it represents a model of operation of the territory applied to monitor phenomena. In particular, for coastal areas the following states and pressures at the regional level or individual physiographic units may be assessed:

i. Sectors and pressures: urbanization, tourism, agriculture, fishing, aquaculture, industry maritime transport;

ii. State and impacts: Land use and coastal erosion/flooding (length of coastlines at risk and population exposed to erosion, flooding from storms, tsunamis), pollution (eutrophication, microbial contamination and risks to human health, heavy metals and compounds organochlorines, oil pollution, radioactive), biodiversity and ecosystem status, salinization, climate change;

iii. Sectors and resource: nature, landscape, archaeology, tourism, economic activities;

iv. Status and value: Areas of environmental, historical and cultural value, "valuable/sustainable" socioeconomic structures, positive and functional management tools.

Another issue that may arise is the necessity for identity and mapping potential environmental hazards. For this purpose, it can be elaborate an Eco-mapping. It represents an environmental management tool that allowing identify and map an inventory of environmental criticalities and problems by detecting the potential sources of pollution, the possible migration paths in environmental matrices and the related impact. The methodology considers the possible impacts affecting the environmental fields of water, air, soil and subsoil, waste, energy consumption, etc. After identifying the sources of environmental hazards, the objectives are defined and based on a specific program of interventions to achieve them. Eco-mapping can be applied in conjunction with SWOT (strengths, weaknesses-opportunities-threats) analysis to combine environmental analysis (obtained with eco-mapping) with the study of development potential (economic-social) of a coast, highlighting the strengths, weaknesses and to bring out the opportunities and threats to development. Finally, an important aspect is the continuous monitoring of the effectiveness of the actions undertaken. This important task will have to be carried out by the observatory. In particular, to assess the effectiveness of the planned actions and the progress of the measures envisaged to reduce the significant pressures identified, a qualitative-quantitative estimate will be made of the variance between the current level of a coastal stretch and the target (environmental, socioeconomic, etc.) to be achieved. This additional level of analysis — defined as "gap analysis" - will allow to evaluate the additional measures that may complement the basic ones, if the last ones prove insufficient to achieve the objectives set for the coastal areas and indicated in the plan.

\section{Conclusions}

Sustainable management of coastal zones inevitably involves tackling the many critical issues affecting these areas, which contribute to triggering various risks for both ecosystems and populations.

Despite numerous international and European studies and projects that have been carried out during the last decades, several critical points are emerging. The resulting problems concern both 
unsustainable coastal management due to the exploitation by human activities and the increase of coastal risks, mainly relating to climate change. From the scenario outlined, emerges the need for an integrated methodology able to combine the sustainable coastal management with the assessment of all the elements influencing coastal risks. In the existing literature, there are various methodologies for integrated coastal zone management. Nevertheless, not much attention is paid to its integration with coastal risks. Effective risk management requires, at first, a clear understanding of the processes that define the intrinsic hazard present in natural areas. This can be achieved by applying an integrated methodology that can be a priority and support the choice of interventions and planning.

A key factor is the application scale of the methodology, which must be sufficiently large to properly assess both the coastal dynamics processes and the socioeconomic factors related to the coastal use. A suitable scale of analysis will provide a wide and complete overview of the coastal area allowing a proper assessment of all the peculiarities and the factors causing the risks. To date, coastal management plans are generally related to administrative boundaries (regional or sub-regional scale). In this context, the starting point should be an updated and homogeneous knowledge base, applied to even very large territories, useful to provide timely and targeted information to adopt effective governance strategies.

By analyzing the significant issues and results of experiences in the national/European/international scientific framework during the last decades, the present work proposes an integrated methodology for sustainable coastal management which also accounts for coastal risks. The main analytical steps to integrate a risk management strategy into a sustainable coastal methodology are defined, as well as its implementation scale. The hierarchical structure of the outlined procedure, the main steps on which it is based and their mutual interconnections are reported. Finally, the limits and barriers to its implementation are discussed.

Effective knowledge exploitation is the new goal for a better decision support, considering that coastal zones are complex systems. In this awareness, any commitments and objectives must be undertaken and supported on various fronts (territorial, environmental, social, economic, etc.) to improve the overall quality of the environment and promote the rational use of natural resources by moving also towards the vision of a circular economy.

Author Contributions: Conceptualization, E.A. and M.M.; methodology, E.A.; writing—original draft preparation, E.A.; writing-review and editing, E.A.; supervision, M.M. All authors have read and agreed to the published version of the manuscript.

Funding: This research received no external funding.

Conflicts of Interest: The authors declare no conflict of interest.

\section{References}

1. Armenio, E.; De Padova, D.; De Serio, F.; Mossa, M. Monitoring system in mar Grande basin (Ionian Sea). In Proceedings of the 2018 IEEE International Workshop on Metrology for the Sea, Bari, Italy, 8-10 October 2018; pp. 104-109. [CrossRef]

2. Armenio, E.; Ben Meftah, M.; Bruno, M.F.; De Padova, D.; De Pascalis, F.; De Serio, F.; Di Bernardino, A.; Mossa, M.; Leuzzi, G.; Monti, P. Semi enclosed basin monitoring and analysis of meteo, wave, tide and current data. In Proceedings of the 2016 IEEE Workshop on Environmental, Energy, and Structural Monitoring Systems (EESMS), Bari, Italy, 13-14 June 2016; pp. 180-185.

3. Barile, S.; De Padova, D.; Mossa, M.; Sibilla, S. Theoretical analysis and numerical simulations of turbulent jets in a wave environment. Phys. Fluids 2020, 32, 035105. [CrossRef]

4. Ben Meftah, M.; De Serio, F.; De Padova, D.; Mossa, M. Hydrodynamic Structure with Scour Hole Downstream of Bed Sills. Water 2020, 12, 186. [CrossRef]

5. Cantasano, N.; Pellicone, G.; Ietto, F. Integrated coastal zone management in Italy: A gap between science and policy. J. Coast. Conserv. 2017, 21, 317-325. [CrossRef] 
6. Ciavola, P.; Valentini, A.; Masina, M.; Armaroli, C. Review of Climate Change Impact on Storm Occurrence. Rapporto Micore D1.4. 2019. Project Deliverable D.1.4 Version 16th July 2009. Available online: http://www.micore.eu/file.php?id=4 (accessed on 28 May 2020).

7. Dessì, F.; Funedda, A.L.; Ghiglieri, G.; Manigas, L.; Marrone, V.A.; Melis, M.T.; Patta, E.D.; Vacca, A. An interdisciplinary approach for the knowledge and management of a small Mediterranean catchment: The experience in the RESMAR Project. In Land Degradation in Mediterranean Environments: Causes, Processes and Management; University of Cagliari: Cagliari, Italy, 2012; p. 21.

8. Directive, Strategy Framework. Directive 2008/56/EC of the European Parliament and of the Council. Council Decision of 17 June 2008. Available online: https://eur-lex.europa.eu/LexUriServ/LexUriServ.do?uri=OJ:L: 2008:164:0019:0040:EN:PDF (accessed on 28 May 2020).

9. Pranzini, E.; Willliams, A.T. Coastal Erosion and Protection in Europe; Routledge: London, UK; New York, NY, USA, 2013; ISBN 978-1-84971-339-9 (hbk), 978-0-203-12855-8 (ebk).

10. Zhang, K.; Douglas, B.C.; Leatherman, S.P. Global warming and coastal erosion. Clim. Chang. 2004, 64, 41. [CrossRef]

11. Nicoletti, L.; Paganelli, D.; Gabellini, M. Environmental Aspects of Relict Sand Dredging for Beach Nourishment: Proposal for a Monitoring Protocol; Quaderno ICRAM; Studio Egocreativo Srl: Roma, Italy, 2006; Volume 5, 155p.

12. Paganelli, D.; La Valle, P.; Ercole, S.; Lisi, I.; Teofili, C.; Nicoletti, L. Linee Guida per gli Studi Ambientali Connessi alla Realizzazione di Opere di Difesa Costiera; Manuali e Linee Guida; ISPRA: Roma, Italy, 2014; 73p.

13. Pranzini, E.; Wetzel, L. Beach Erosion Monitoring—Results from BEACHMED-e/OpTIMAL Project; Nuova Grafica Fiorentina: Marino, Italy, 2008; 230p.

14. Pranzini, E. Shore protection in Italy: From hard to soft engineering ... and back. Ocean Coast. Manag. 2018, 156, 43-57. [CrossRef]

15. Ciavola, P.; Valentini, A.; Masina, M.; Armaroli, C. Review of Climate Change Impact on Storm Occurrence; Rapporto Micore D1.4; Ferreira, O., Vousdoukas, M., Ciavola, P., Eds.; 2009; Available online: https://www.micore.eu/file.php?id=4 (accessed on 28 May 2020).

16. Barbano, A.; Braca, G.; Bussettini, M.; Dessì, B.; Inghilesi, R.; Lastoria, B.; Spizzichino, D. Proposta metodologica per l'aggionamento delle mappe di pericolosità e di rischio-Attuazione della Direttiva 2007/60/CE relativa alla valutazione e alla gestione dei rischi da alluvioni (Decreto Legislativo n. 49/2010). ISPRA Man. Linee Guid. 2012, 82, 2012.

17. Bruno, M.F.; Molfetta, M.G.; Pratola, L.; Mossa, M.; Nutricato, R.; Morea, A.; Nitti, D.O.; Chiaradia, M.T. A combined approach of field data and earth observation for coastal risk assessment. Sensors 2019, 19, 1399. [CrossRef]

18. Communication from the Commission to the Council of the European Parliament. Towards an Integrated Maritime Policy for a Better Governance of the Mediterranean; COM: Luxemburg, 2009; p. 466.

19. Denaro, R.; Mazzola, S.; Yakimov, M.M.; Giuliano, L. RITMARE Italian research and industry for the sea. In Marine biotechnology in the European research area: Challenges and opportunities for Europe. Final CSA Mar. Biotech Conf. 2013, 64, 43.

20. EC Luxembourg. Living with Coastal Erosion in Europe; EU Publication: Luxemburg, 2007 ; p. 40. ISBN 978-92-79-06194-3.

21. Malvárez, G.C.; Pintado, E.G.; Navas, F.; Giordano, A. Spatial data and its importance for the implementation of UNEP MAP ICZM Protocol for the Mediterranean. J. Coast. Conserv. 2015, 19, 633-641. [CrossRef]

22. Directive 2014/89/EU of the European Parliament and of the Council of 23 July 2014. Available online: https://eur-lex.europa.eu/legal-content/EN/TXT/PDF/?uri=CELEX:32002H0413\&from=SV (accessed on 28 May 2020).

23. Meiner, A. Integrated maritime policy for the European Union-Consolidating coastal and marine information to support maritime spatial planning. J. Coast. Conserv. 2010, 14, 1-11. [CrossRef]

24. Prem, M. Implementation obstacles of the ICZM protocol and mitigation efforts. J. Coast. Conserv. 2010, 14, 257-264. [CrossRef]

25. Recommendation 2002/413/EC of the European Parliament and of the Council on the implementation of integrated coastal zone management in Europe, Official Journal L 148, 06/06/2002 pp. 0024-0027. 30 May 2002. Available online: https://www.eumonitor.eu/9353000/1/j9vvik7m1c3gyxp/vitgbgirorzt (accessed on 28 May 2020). 
26. Van Assche, K.; Hornidge, A.K.; Schlüter, A.; Vaidianu, N. Governance and the coastal condition: Towards new modes of observation, adaptation and integration. Mar. Policy 2019, 1-10. [CrossRef]

27. Preliminary Document for the Formulation of the Guidelines and Criteria for the Defense of the Coasts; Ministry of the Environment and Protection of the Territory and the Sea: Roma, Italy, 2006.

28. De Padova, D.; De Serio, F.; Mossa, M.; Armenio, E. Investigation of the current circulation offshore Taranto by using field measurements and numerical model. In Proceedings of the 2017 IEEE International Instrumentation and Measurement Technology Conference (I2MTC), Turin, Italy, 22-25 May 2017.

29. Eurosion. Living with Coastal Erosion in Europe: Sediment and Space for Sustainability; European Commission: Brussels, Belgium, 2004.

30. MATTM-Regioni. Linee Guida per la Difesa della Costa dai Fenomeni di Erosione e Dagli Effetti dei Cambiamenti Climatici. Versione Aggiornata—Documento Elaborato dal Tavolo Nazionale sull'Erosione Costiera MATTM-Regioni con il Coordiamento Tecnico di; ISPRA: Rome, Italy, 2018; 305p.

31. MATTM. Documento Preliminare per L'individuazione Degli Indirizzi e dei Criteri per la Difesa Della Costa. Ministry of the Environment and Protection of the Territory and the Sea: Rome, Italy, 2006.

32. Saaty, T.L. A scaling method for priorities in hierarchical structures. J. Math. Psychol. 1977, 15, $234-281$. [CrossRef]

33. Saaty, T.L.; Vargas, L.G. Prediction, Projection, and Forecasting: Applications of the Analytic Hierarchy Process in Economics, Finance, Politics, Games, and Sport; Springer: Heidelberg, Germany, 1991.

34. Chiaradia, M.T.; Francioso, R.; Matarrese, R.; Petrillo, A.F.; Ranieri, G.; Urrutia, C. Estrazione semi-automatica della linea di costa da immagini satellitari ad alta risoluzione: Valutazione ed applicabilità. Collana Editor. Studi Ric. Aut. Bacino Basilicata 2008, 9, 2008.

35. Grande, V.; Proietti, R.; Foglini, F.; Remia, A.; Correggiari, A.; Paganelli, D.; Targusi, M.; Franceschini, G.; La Valle, P.; Berducci, M.T.; et al. Sistema Informativo per il Monitoraggio Ambientale della Risorsa Sabbia Offshore nei Progetti di Protezione Costiera: Geodatabase env_Sand; Manuali e Linee guida; ISPRA: Rome, Italy, 2015; 63p.

36. Karim, M.S.; Hoque, R. Integrated coastal zone management and sustainable development of Coastal Area: A short overview of International Legal Framework. In Integrated Coastal Zone Management; Moksness, E., Dahl, E., Støttrup, J., Eds.; Wiley-Blackwell: Oxford, UK, 2009; Chapter 13; pp. 170-179.

37. Project PESETA-Coastal Systems Study, Joint Research Centre Institute for Prospective Technological Studies. Impacts of Climate Change in Coastal Systems in Europe. Luxembourg. 2009. Available online: http://ipts.jrc.ec.europa.eu/publications/pub.cfm?id=2979 (accessed on 28 May 2020).

38. Project MICORE, 7FP. Available online: http://www.micore.eu (accessed on 28 May 2020).

39. Rapport du Comité National de Suivi de la Stratégie nationale de gestion integrée su trait de côte " 40 mesures puor l'adaptation des territories littoraux au changement climatique", Comité national de suivi-Rapport 40 mesures-ottobre 2015. Available online: http://docplayer.it/118936879-Tavolo-nazionale-sull-erosionecostiera.html (accessed on 28 May 2020).

40. De Pascalis, F.; Ghezzo, M.; Umgiesser, G.; De Serio, F.; Mossa, M. Use of SHYFEM Open Source Hydrodynamic Model for Time Scales Analysis in a Semi-enclosed Basin. In Proceedings of the 2016 IEEE Workshop on Environmental, Energy, and Structural Monitoring Systems (EESMS), Bari, Italy, 13-14 June 2016; pp. 1-4.

41. De Serio, F.; Mossa, M. Assessment of hydrodynamics, biochemical parameters and eddy diffusivity in a semi-enclosed Ionian basin. Deep Sea Res. Part II Top. Stud. Oceanogr. 2016, 133, 176-185. [CrossRef]

42. Mossa, M.; Meftah, M.B.; De Serio, F.; Nepf, H.M. How vegetation in flows modifies the turbulent mixing and spreading of jets. Sci. Rep. 2017, 7, 1-14. [CrossRef]

43. Directive 2007/60/EC of the European Parliament and of the Council of 23 October 2007 on the Assessment and Management of Flood Risks. OJ L 288, 06/11/2007, pp. 27-34. Available online: https://www.eea.europa. eu/policy-documents/directive-2007-60-ec-of (accessed on 28 May 2020).

44. Tognin, D.; Peruzzo, P.; De Serio, F.; Ben Meftah, M.; Carniello, L.; Defina, A.; Mossa, M. Experimental setup and measuring system to study solitary wave interaction with rigid emergent vegetation. Sensors 2019, 19, 1787. [CrossRef]

45. Chen, S.N.; Pearson, S. Managing China's coastal environment: Using a legal and regulatory perspective. Int. J. Environ. Sci. Dev. 2015, 6, 225. [CrossRef]

46. Cooper, J.A.G. Progress in integrated coastal zone management (ICZM) in Northern Ireland. Mar. Policy 2011, 35, 794-799. [CrossRef]

47. Hegde, A.V. Coastal Erosion and Mitigation Methods-Global State of Art. Indian J. Geo-Mar. Sci. 2010, 39, 521-530. 
48. Wang, X.H.; Xu, X.; Pearson, S.G.; Xue, G.; Morrison, R.J.; Liu, D.; Shi, P. Integrated Coastal Zone Management Research in Australia and China. Labour Manag. Develop. J. 2011, 11, 1-17.

49. IPCC $5^{\circ}$ Assessment Report. Available online: https://www.ipcc.ch/pdf/assessment-report/ar5/syr/SYR_ AR5_FINAL_full.pdf (accessed on 28 May 2020).

50. De Serio, F.; Mossa, M. Experimental Observations of Turbulent Events in the Surfzone. J. Mar. Sci. Eng. 2019, 7, 332. [CrossRef]

51. De Serio, F.; Mossa, M. Meteo and Hydrodynamic Measurements to Detect Physical Processes in Confined Shallow Seas. Sensors 2018, 18, 280. [CrossRef] [PubMed]

52. De Serio, F.; Mossa, M. Environmental monitoring in the Mar Grande basin (Ionian Sea, Southern Italy). J. Environ. Sci. Pollut. Res. 2016, 23, 12662-12674. [CrossRef] [PubMed]

53. Ferretti, O.; Del Bono, I.; Furia, S.; Barsantui, M. Difese Costiere Morbide: Ripascimenti Artificiali-Rassegna Tipologica. In Elementi di Gestione Costiera, Parte Quarta; ENEA RT/2003/45/CLIM; 2003; p. 48. ISSN 0393-3016.

54. Mossa, M. Field measurements and monitoring of wastewater discharge in sea water. Estuar. Coast. Shelf Sci. 2006, 68, 509-514. [CrossRef]

55. Central Dredging Association (CEDA). Information Paper Environmental Monitoring Procedures; CEDA: Delft, The Netherlands, 2015.

56. Cipriani, L.E. Coastal Erosion Monitoring. A Network of Regional Observatories-Results from RESMAR Project; Nuova Grafica Fiorentina: Firenze, Italy, 2013; 244p.

57. Armenio, E.; De Padova, D.; De Serio, F.; Mossa, M. Monitoring System for the Sea: Analysis of Meteo, Wave and Current Data. In Proceedings of the IMEKO TC19 Workshop on Metrology for the Sea, Naples, Italy, 11-13 October 2017; pp. 143-148.

58. Armenio, E.; De Serio, F.; Mossa, M.; Nobile, B.; Petrillo, A.F. Investigation on coastline evolution using long-term observations and numerical modelling. In Proceedings of the 27th International Ocean and Polar Engineering Conference, San Francisco, CA, USA, 25-30 June 2017.

59. Armenio, E.; Serio, F.; De Mossa, M. An approach for data-driven characterization of tide and current fluxes in coastal basins. Hydrol. Earth Syst. Sci. 2016, 21, 1-14.

60. European Commission. Eurosion Report, Raccomandazione n.1; European Commission: Brussels, Belgium, 2004.

61. Water Framework Directive (WFD) 2000/60/EC: Directive 2000/60/EC of the European Parliament and of the Council of 23 October 2000 establishing a framework for Community action in the field of water policy. Available online: https:/eur-lex.europa.eu/legal-content/EN/TXT/?uri=celex:32000L0060 (accessed on 28 May 2020).

62. Armenio, E.; Meftah, M.B.; Capasso, G.; Corbelli, V.; De Padova, D.; De Pascalis, F.; Di Bernardino, A.; Leuzzi, G.; Monti, P.; Pini, A.; et al. Detecting sensitive areas in confined shallow basins. Environ. Model. Softw. 2020, 126, 104659.

63. Ciavola, P.; Ferreira, O.; Haerens, P.; Van Koningsveld, M.; Armaroli, C. Storm Impacts along European Coastlines. Part 2: Lessons Learned from the MICORE Project. Environ. Sci. Policy 2011, 14, 924-933. [CrossRef]

64. Armenio, E.; Ben Meftah, M.; De Padova, D.; De Serio, F.; Mossa, M. Monitoring systems and numerical models to study coastal sites. Sensors 2019, 19, 1552. [CrossRef] [PubMed]

65. Cipriani, L.E.; Pranzini, E. Le Ricadute del Progetto BEACHMED-e OpTIMAL Sulle Strategie di Monitoraggio Dell'erosione Costiera in Toscana; Proceedings Coste: Prevenire, Programmare, Pianificare. Matera, Italy, 2008. Available online: https:/unige.it/consulenze/docs/curriculum-28051.pdf (accessed on 28 May 2020).

(C) 2020 by the authors. Licensee MDPI, Basel, Switzerland. This article is an open access article distributed under the terms and conditions of the Creative Commons Attribution (CC BY) license (http://creativecommons.org/licenses/by/4.0/). 